\title{
Voluntary exercise improves hypothalamic and metabolic function in obese mice
}

\author{
Brenton T Laing1,2, Khoa Do1,2,*, Tomoko Matsubara1,2, David W Wert2, \\ Michael J Avery', Erin M Langdon', Donghai Zheng1,2,3 and Hu Huang1,2,3,4 \\ 1Department of Kinesiology, East Carolina University, Greenville, North Carolina, USA \\ 2East Carolina Diabetes and Obesity Institute, East Carolina University, Greenville, North Carolina, USA \\ 3Human Performance Laboratory, Collage of Human Performance and Health, East Carolina University, \\ Greenville, North Carolina, USA \\ ${ }^{4}$ Department of Physiology, East Carolina University, Greenville, North Carolina, USA \\ (*B T Laing and K Do contributed equally to this work)
}

Correspondence

should be addressed to

H Huang

Email

huangh@ecu.edu

\begin{abstract}
Exercise plays a critical role in regulating glucose homeostasis and body weight. However, the mechanism of exercise on metabolic functions associated with the CNS has not been fully understood. C57BL6 male mice $(n=45)$ were divided into three groups: normal chow diet, high-fat diet (HFD) treatment, and HFD along with voluntary running wheel exercise training for 12 weeks. Metabolic function was examined by the Comprehensive Lab Animal Monitoring System and magnetic resonance imaging; phenotypic analysis included measurements of body weight, food intake, glucose and insulin tolerance tests, as well as insulin and leptin sensitivity studies. By immunohistochemistry, the amount changes in the phosphorylation of signal transducer and activator of transcription 3, neuronal proliferative maker Ki67, apoptosis positive cells as well as pro-opiomelanocortin (POMC)-expressing neurons in the arcuate area of the hypothalamus was identified. We found that 12 weeks of voluntary exercise training partially reduced body weight gain and adiposity induced by an HFD. Insulin and leptin sensitivity were enhanced in the exercise training group verses the HFD group. Furthermore, the HFD-impaired POMC-expressing neuron is remarkably restored in the exercise training group. The restoration of POMC neuron number may be due to neuroprotective effects of exercise on POMC neurons, as evidenced by altered proliferation and apoptosis. In conclusion, our data suggest that voluntary exercise training improves metabolic symptoms induced by HFD, in part through protected POMC-expressing neuron from HFD and enhanced leptin signaling in the hypothalamus that regulates whole-body energy homeostasis.
\end{abstract}

\section{Introduction}

Obesity is reaching epidemic proportions in North America, affecting American society with increased morbidity and mortality as well as economic cost (Kopelman 2000). Obesity is usually associated with
Key Words
- hypothalamus
- exercise
- metabolism
- mouse
- obesity 
respond to physiological changes such as hunger and satiety by secreted cytokines or hormones. Distinct nuclei within the hypothalamus such as arcuate (ARC), the paraventricular nucleus, the ventromedial hypothalamus $(\mathrm{VMH})$, the dorsomedial hypothalamus $(\mathrm{DMH})$, and the lateral hypothalamus share neuronal interconnections to maintain body homeostasis (Mayers \& Olson 2012). Although many neurons in the hypothalamus regulate metabolic functions, pro-opiomelanocortin (POMC)expressing neurons, located in the ARC area, is a key regulator of energy metabolism. Genetic ablation of Pomc neurons causes increased food intake and reduced energy expenditure, leading to characteristics of the obese phenotype such as increased body weight and adiposity (Greenman et al. 2013, Zhan et al. 2013). Conversely, activation of POMC neurons suppresses food intake, increases energy expenditure, and induces the characteristics of the lean phenotype, such as decreased body weight and adiposity (Zhan et al. 2013). This indicates that POMC neurons play critical roles in body weight regulation. More specifically, because overnutrition and high-fat diet (HFD) induce hypothalamic dysfunctions, contributing to obesity and insulin resistance often leading to type 2 diabetes (Zhang et al. 2008). HFD specifically and preferentially affects POMC neurons in the ARC. This suggests that POMC neurons are the target and part of the mechanism of HFD-induced obesity and diabetes (Li et al. 2012).

Exercise therapy is a proven and effective clinical intervention for treating obesity and related diseases, such as hyperlipidemia and type 2 diabetes mellitus (Tremblay et al. 1985). Exercise stimulates glucose uptake by skeletal muscle from the blood (Goldstein et al. 1953), decreases fat content from the adipose tissue (Gollisch et al. 2009), and prevents fat accumulation in the liver (Jackson et al. 2011). Besides the effects of exercise on peripheral tissues, voluntary exercise also improves brain function. For instance, it enhances learning and memory ability associated with the hippocampal area of the brain to prevent cognitive dysfunction and Alzheimer's disease (Trejo et al. 2008, Fuss et al. 2010, Erickson et al. 2011).

Historical studies have demonstrated the effects of exercise on the CNS that uses neurotransmitters and trophic factors involved in energy homeostasis, such as norepinephrine, $\gamma$-amino butyric acid, serotonin (5-HT; Dishman 1997), and brain-derived neurotrophic factor (BDNF; Neeper et al. 1996). Furthermore, 40-day voluntary running wheel training significantly increases neuropeptide Y gene expression in Sprague-Dawley male rat ARC nucleus and DMH (Lewis et al. 1993). Recently, it has been reported that hypothalamic melanocortin receptor (MCR) expression has been associated with the exercise activity and nonexercise activity thermogenesis (Shukla et al. 2015). Although we have gained a better understanding that hypothalamic MCR signaling is highly regulated by the products of Pomc-expressing neurons (Bagnol et al. 1999), little is known about how exercise improves metabolic function via hypothalamic POMC-expressing neurons. In light of this gap, we sought to investigate the effects of voluntary exercise training on whole-body metabolic parameters and hypothalamic POMC neuron function in the diet-induced obese mice.

\section{Materials and methods}

\section{Experimental animals}

Eight-week-old C57BL6 male mice $(n=45)$ from Jackson lab (The Jackson Laboratory, Bar Harbor, ME, USA) were housed under controlled temperature and lighting conditions of $20-22^{\circ}$ and 12-h light:12-h darkness cycle. Once the experimental protocol was initiated, all mice were divided into three groups: chow group (control; $n=15$ with regular diet containing $26 \%$ protein, $14 \%$ fat, and $60 \%$ carbohydrate), HFD group ( $n=15,16 \%$ protein, $58 \%$ fat, and 26\% carbohydrate, Research Diets D12331; Research Diets, Inc., New Brunswick, NJ, USA), and HFD with exercise training (HFD $+\mathrm{EX} ; n=15,16 \%$ protein, $58 \%$ fat, and 26\% carbohydrate, Research Diets D12331) and voluntary running wheel (TSE PhenoMaster System, Bad Homburg, Germany) for 12 weeks. For the study of voluntary wheel running, age-matched animals in the HFD + EX group were placed in cages equipped with running wheels for mice (TSE PhenoMaster), whereas animals in the control group and HFD group were housed in cages without running wheels for 12 weeks. Each cage accommodated one mouse. All aspects of animal care and experimentation were conducted in accordance with the National Institutes of Health Guide for the Care and Use of Laboratory Animals (National Institutes of Health Publication no. 85-23, revised 1996) and approved by the Institutional Animal Care and Use Committees of East Carolina University (Greenville, NC, USA).

\section{Energy intake, energy expenditure, and body composition}

Food intake was measured over a 5- to 7-day period, and the data were combined, averaged, and analyzed. Fresh pellets of food were provided every day to avoid

Published by Bioscientifica Ltd. 
temperature-dependent spoilage to the HFD group, and cages were changed every time that food weight was measured. Any residual bits of food in the bedding were included in measurements. Cumulative food intake data were obtained by adding all intake measurements during the study.

Fat and lean body mass were assessed using Echo MRI (Echo Medical Systems, Houston, MA, USA). Energy expenditure was measured by assessing oxygen consumption and carbon dioxide production using an indirect calorimetry with Comprehensive Lab Animal Monitoring System (CLAMS; TSE PhenoMaster). Mice were acclimated in the CLAMS chambers for $72 \mathrm{~h}$ before data collection, and had free access to food and water for the duration of the studies.

\section{Glucose tolerance test and insulin tolerance test}

Two weeks before the last day of the experiment, an intraperitoneal glucose tolerance test (IPGTT) and an intraperitoneal insulin tolerance test (IPITT) were performed. After an overnight fast, IPGTT was performed by intraperitoneal injection of a 20\% glucose solution $(1 \mathrm{~g} / \mathrm{kg})$. Blood samples were collected before and 15, 30, 60, 90, and $120 \mathrm{~min}$ after the injection. For IPITT, after a 4-h fast, an intraperitoneal injection of $1 \mathrm{IU} / \mathrm{kg}$ human rapid insulin (Eli Lilly) was administered to the HFD-treated mice and $0.5 \mathrm{U} / \mathrm{kg}$ human rapid insulin was administered to the chow diet-treated mice. Blood samples were collected before and 15, 30, 60, 90, and 120 min after the injection. For the IPITT, the response of blood glucose levels was expressed as a percentage of the values before insulin injections.

\section{Morphological analysis of the liver and white adipose tissue}

Serial sections ( $5 \mu \mathrm{M}$ thickness) were taken from the post-fixed liver and epididymal fat, followed by hematoxylin and eosin (H\&E) staining as described previously (Huang et al. 2013). The stained sections were photographed digitally using an optical microscope (Leica DM6000, Germany), and the images were transferred to the computer medium.

\section{Immunohistochemistry}

For fluorescence detection of POMC, coronal brain sections from 20-week-old mice in three groups were generated, and immunohistochemistry was performed as described previously (Huang et al. 2012). Briefly, brain sections were incubated with antibody to POMC (Phoenix Pharmaceuticals, Burlingame, CA, USA) and further incubated with fluorescent-labeled secondary antibodies. POMC-positive neurons throughout the mediobasal hypothalamus were counted using ImageJ software (NIH, Bethesda, MD, USA). Three serial sections were analyzed in each mouse $(n=3)$.

\section{Leptin-induced signal transducer and activator of transcription 3 phosphorylation}

Mice were injected with leptin (A.F. Parlow National Hormone and Peptide Program, Torrance, CA, USA) intraperitoneally $(3 \mathrm{mg} / \mathrm{kg})$ and killed $30 \mathrm{~min}$ later. The brain sections were evaluated for phosphorylatedSTAT3 (pSTAT3) in hypothalamus neurons as described previously (Huang et al. 2012). Briefly, brain sections were incubated with an anti-pSTAT3 antibody (Cell Signaling), followed by an anti-fluoresces-conjugated rabbit antibody, pSTAT3 was then visualized under an optical microscope (Leica DM6000). All pSTAT3immunoreactive ARC neurons were counted using ImageJ software (NIH). Cells within the median eminence were excluded from these analyses. Three serial sections were analyzed in each mouse $(n=3)$.

\section{Insulin signaling and immunoblotting analysis}

After overnight fasting, mice were injected intraperitoneally with human insulin (10 unit/kg of body weight; Humulin R, Eli Lilly) or saline and killed 10 min later. Gastrocnemius muscle was rapidly removed and snap frozen in liquid nitrogen and stored at $-80^{\circ} \mathrm{C}$ until analysis. Muscle lysis (60 $\mu$ g protein) was separated by SDS-PAGE and transferred onto nitrocellulose membranes. The membranes were incubated with polyclonal antibodies against phosphorylation of Serine 473 of AKT and total AKT (Cell Signaling). The bands were visualized with enhanced chemiluminescence and quantified by densitometry. The levels of phosphorylation of AKT on Serine 473 were normalized by total AKT protein levels.

\section{Proliferative assay and tunnel assay}

An endogenous proliferative marker Ki67 was used to determine the neuronal proliferation. Briefly,

Published by Bioscientifica Ltd 
A

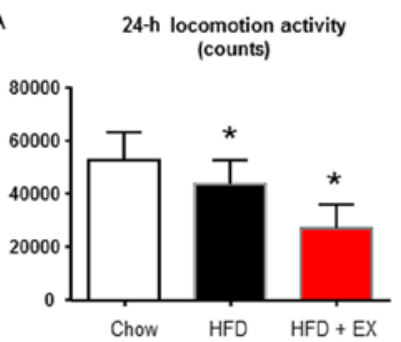

C Body weight before (g)
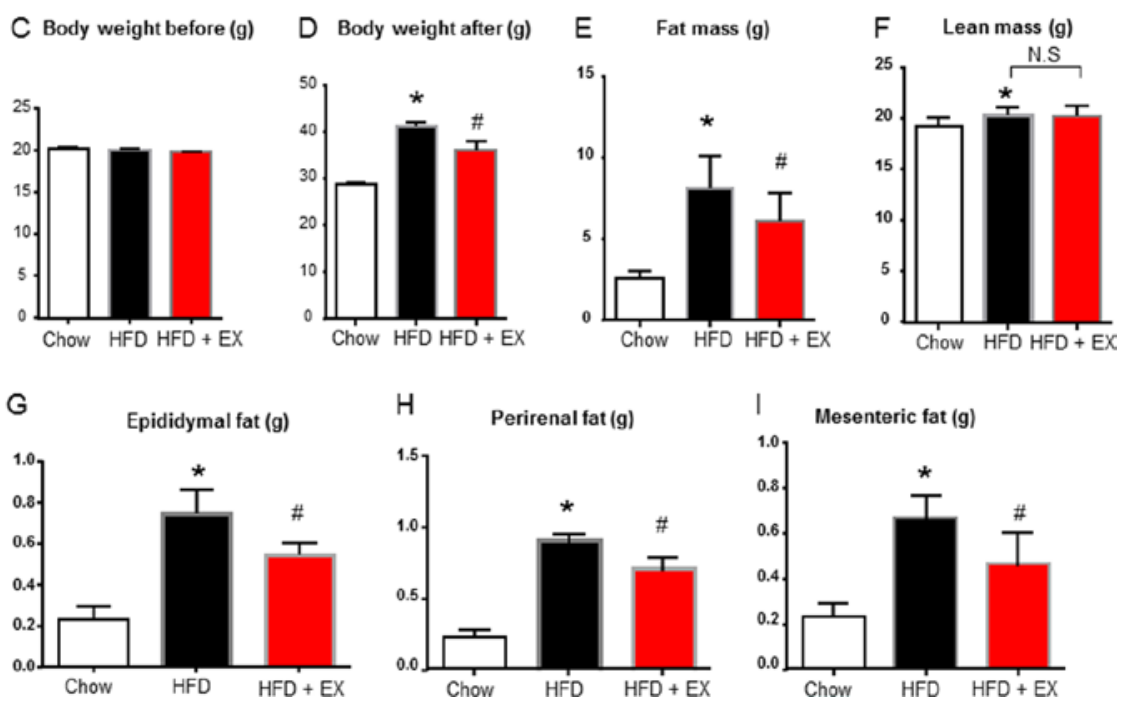

Figure 1

Long-term voluntary exercise training improves HFD-induced body weight gain and adiposity. (A) Average 24-h locomotion activity and (B) running distance in the control, HFD, and HFD + EX groups. (C) Body weight at the beginning of study (aged 8 weeks) and (D) body weight at the end of study (aged 20 weeks) in the control, HFD, and HFD + EX groups. (E) Fat mass and $(F)$ lean mass in 18-week-old male mice. (G) Epididymal, $(\mathrm{H})$ perirental, and (I) mesenteric fat contents at 20 weeks of age $(n=10) ;{ }^{\star} P<0.05$ vs control group, $\# P<0.05$ vs HFD group. A full colour version of this figure is available at http://dx.doi.org/10.1530/JOE-15-0510.
Ki67 antibody (Abcam) was used for a single immunolabeling study in brain sections among the three groups, followed by an anti-fluoresces-conjugated rabbit antibody. Ki67-positive cells throughout the mediobasal hypothalamus were counted using ImageJ software (NIH). Three serial sections were analyzed in each mouse $(n=3)$.

A terminal deoxynucleotidyl transferase-mediated dUTP nick end-labeling (TUNEL) assay was used to identify double-stranded DNA fragmentation. Briefly, coronal brain sections were washed in PBS, transferred to blocking solution for $2 \mathrm{~h}$, and then incubated in primary POMC antibody (Phoenix Pharmaceuticals) overnight. The next day, after washing, the sections were transferred to secondary antibody for $2 \mathrm{~h}$ in light-deprived conditions. After being washed in PBS, samples were incubated at $4^{\circ} \mathrm{C}$ in permeability solution (PBS, $0.1 \%$ Triton-X, $0.1 \%$ sodium citrate) for $2 \mathrm{~min}$, and then incubated with TUNEL assay solution (In Situ Cell Death Detection Kit, Fluorescein, Sigma-Aldrich) for $1 \mathrm{~h}$ at $37^{\circ}$. After being washed in PBS, all sections were mounted on slides with Vectashield antifade reagent. Negative and positive controls for the TUNEL assay were confirmed by staining the sections in the same manner without primary antibody (negative control) or pretreated with DNAse I (positive control).
Positive cells were counted in the ARC from slides $(n=3)$ of each group.

\section{Statistical analysis}

Data are expressed as mean \pm S.E.M. Differences between groups were compared for statistical significance by ANOVA or Student's $t$-test; $P<0.05$ denoted significance.

\section{Results}

\section{Long-term voluntary exercise training lowers body weight gain and adiposity induced by HFD}

To determine the effects of long-term voluntary running wheel exercise training on body weight regulation and adiposity, 45C57BL6 male mice were divided into three groups (control, HFD, and HFD + EX) for 12 weeks. Figures $1 \mathrm{~A}$ and $\mathrm{B}$ show the average daily locomotion activity and running distance, respectively. Although HFD groups show lowered locomotion activity compared with the control group, the HFD + EX group shows significantly increased daily running distance, indicating increased total daily physical activity in the HFD + EX group. Next, 
A Daily food intake (calories)

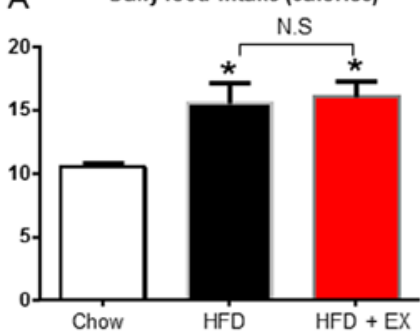

C Oxygen consumption
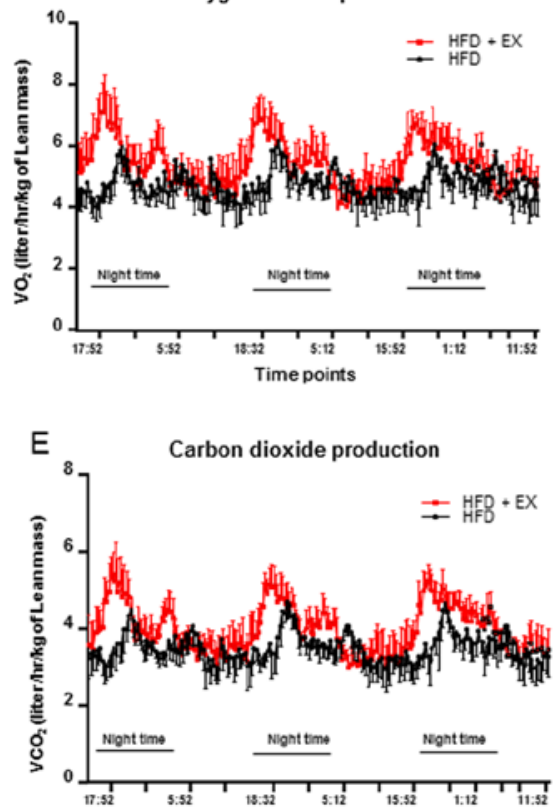

B Weekly food intake (calories)

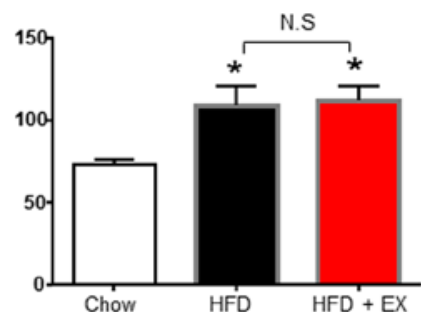

D Day time
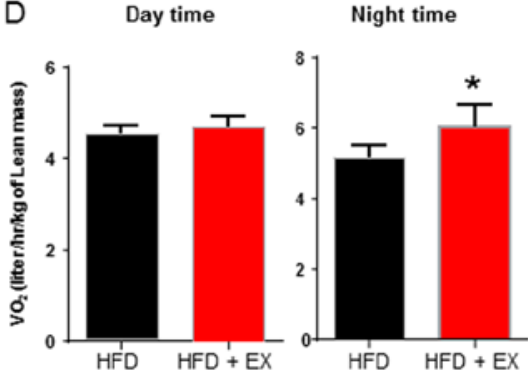

F

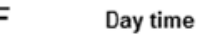

Night time

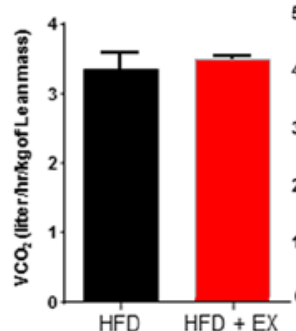

Night time

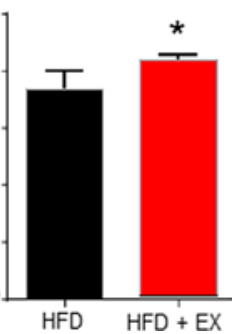

Figure 2

Energy intake and energy expenditure in control, HFD, and HFD + EX groups. (A) Daily food intake and (B) weekly food intake assessed on singly housed male aged $12-13$ weeks. ${ }^{*} P<0.05$ vs control group. (C) Hourly averages of oxygen consumption and (D) corresponding 12-h average during day and night phases of oxygen consumption. (E) Hourly averages of carbon dioxide production and (F) corresponding 12-h average during day and night phases of carbon dioxide production at the age of 18 weeks in HFD and HFD + EX groups $(n=10),{ }^{*} P<0.05$ vs HFD group. A full colour version of this figure is available at http://dx.doi.org/10.1530/JOE-15-0510. we measured the body weight before and after the study, as shown in Figs. 1C and D; there was no difference in body weight among the three groups at the beginning of the study. However, the HFD group significantly increased body weight compared with the control group $(41.1 \pm 0.4$ vs $28.9 \pm 1.1 \mathrm{~g})$ after 12 weeks, and voluntary exercise training significantly lowered HFD-induced body weight gain $(36.3 \pm 1.7$ vs $41.1 \pm 0.4 \mathrm{~g})$ at the end of the study.

Echo MRI data revealed that 12 weeks of HFD increased total fat mass significantly compared with the control group (Fig. 1E; $8.1 \pm 1.9$ vs $2.5 \pm 0.4 \mathrm{~g}$ ). Data also indicated that 12 -week of voluntary running wheel exercise training significantly reduced total fat mass $(6.1 \pm 1.7$ vs $8.1 \pm 1.9 \mathrm{~g})$ compared with the HFD group. There was no significant difference in total lean mass between the HFD groups (Fig. 1F).

By the end of the study, some regional fat pads were harvested and fat contents were weighed. Fat contents such as epididymal fat content (Fig. $1 \mathrm{G} ; 0.61 \pm 0.10 \mathrm{vs}$ $0.75 \pm 0.07 \mathrm{~g}$ ), perineal fat content (Fig. $1 \mathrm{H} ; 0.72 \pm 0.06$ vs $0.91 \pm 0.03 \mathrm{~g}$ ), as well as mesenteric fat (Fig. 1I; $0.47 \pm 0.09$ vs $0.67 \pm 0.12 \mathrm{~g}$ ) were significantly decreased in the HFD + EX group compared with the HFD group. Voluntary exercise training reduces body weight via increased energy expenditure despite normal caloric intake in HFDs.

Change in body weight is controlled by energy intake and energy expenditure. To assess energy intake, food was weighed daily. Daily and cumulative caloric intake in all three groups was calculated at week 8 after the start date. At this point, although there was a significant increase in calorie intake in the HFD groups compared with the control group, we did not observe any caloric intake difference between the HFD and the HFD + EX groups (Fig. 2A and B). Energy expenditure, as measured by oxygen consumption over $24 \mathrm{~h}$, was significantly increased in the HFD + EX group $(5.32 \pm 0.66$ vs $4.72 \pm 0.48 \mathrm{~L} / \mathrm{h} / \mathrm{kg}$ of lean mass) only during the night (Fig. 2C and D). Similarly, the total amount of carbon dioxide production over $24 \mathrm{~h}$ was also significantly increased in the HFD + EX group compared

Published by Bioscientifica Ltd. 
A Fasting glucose

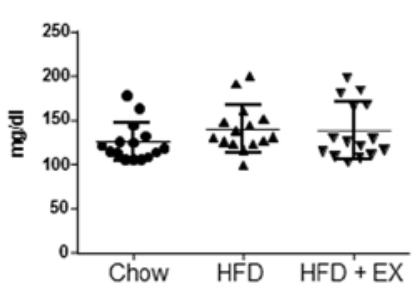

C

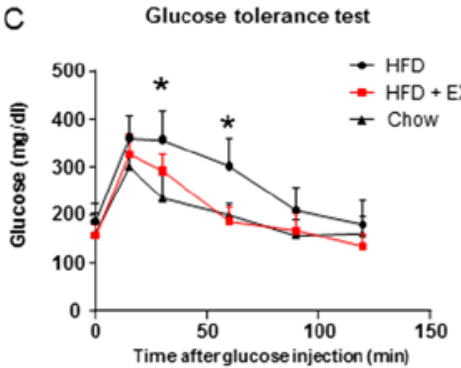

$E$

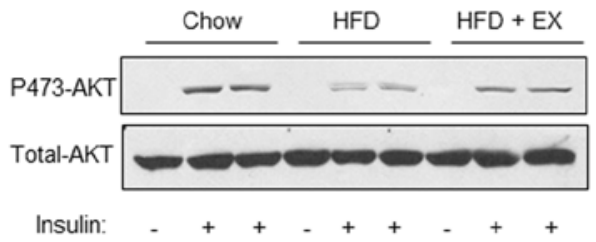

B
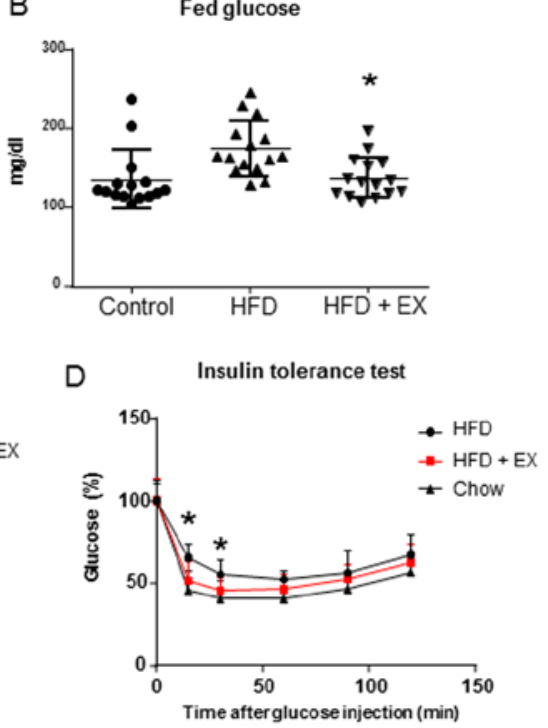

F Skeletal muscle phosphorylation/Total AKT

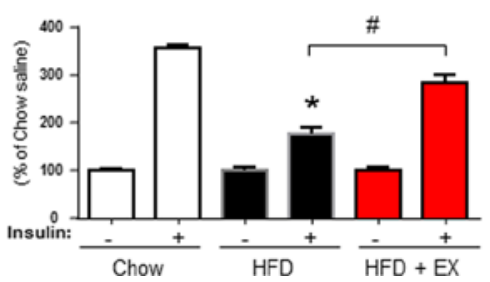

Figure 3

Long-term voluntary exercise training improves fed glucose levels and insulin sensitivity. (A) Fasted and (B) fed glucose levels at the age of 19 weeks, ${ }^{*} P<0.05$ vs HFD group. (C) Glucose tolerance test and (D) insulin tolerance test were accessed in the control, HFD, and HFD + EX groups at the age of 18 and 19 weeks old, respectively $(n=15), * P<0.05$ vs HFD group. (E) The representative of western blot and (F) normalized graphs show insulin signaling in skeletal muscle by the end of the study in the control, HFD, and HFD + EX groups $(n=3) ; * P<0.05$ vs control group, ${ }^{*} P<0.05$ vs HFD group. A full colour version of this figure is available at http://dx.doi.org/10.1530/JOE-15-0510. with the HFD group $(3.92 \pm 0.62$ vs $3.52 \pm 0.39 \mathrm{~L} / \mathrm{h} / \mathrm{kg}$ of lean mass) only during the night (Fig. 2E and F).

\section{Long-term exercise training improves insulin sensitivity in HFD}

To determine whether long-term voluntary exercise training can improve insulin sensitivity impaired by HFD, we measured both fasted and fed status glucose levels at 19 weeks of age. Although there was no significant difference in fasting plasma glucose levels between the HFD + EX and the HFD groups, fed plasma glucose levels in the HFD + EX group were significantly reduced compared with the HFD group (Fig. $3 \mathrm{~A}$ and B). A glucose tolerance test also revealed that glucose tolerance was significantly improved in the HFD + EX group versus the HFD group, especially after 30 and $60 \mathrm{~min}$ of glucose injection (Fig. 3C). The insulin tolerance test also showed improvement associated with exercise training, with peak differences after 15 and $30 \mathrm{~min}$ of the insulin injection. This indicates that long-term exercise training improves systemic insulin sensitivity (Fig. 3D).
(C) 2016 Society for Endocrinology Printed in Great Britain
In support of the notion that long-term exercise training improves systemic insulin sensitivity in the HFD + EX group, insulin signaling in skeletal muscle was examined by immunoblotting for phosphorylation of AKT (protein kinase B) in gastrocnemius. Figure 3E and F shows that skeletal muscle phosphorylation of AKT was significantly impaired in the HFD group compared with the control group, and voluntary exercise training remarkably reversed skeletal muscle phosphorylation of AKT in the HFD+EX group, indicating that there is significant improvement in skeletal muscle insulin signaling (Fig. 3E and F).

\section{Voluntary exercise training reduces HFD-induced lipid accumulation in the liver and adipocytes size in white adipose tissue}

Histological analysis shows that 12 weeks of HFD significantly increased lipid accumulation in the liver revealed by H\&E stain in liver sample sections, whereas voluntary exercise training remarkably reduced lipid accumulation in the liver (Fig. 4, left). In white adipose tissue, the cell size in HFD group mice was significantly

Published by Bioscientifica Ltd 


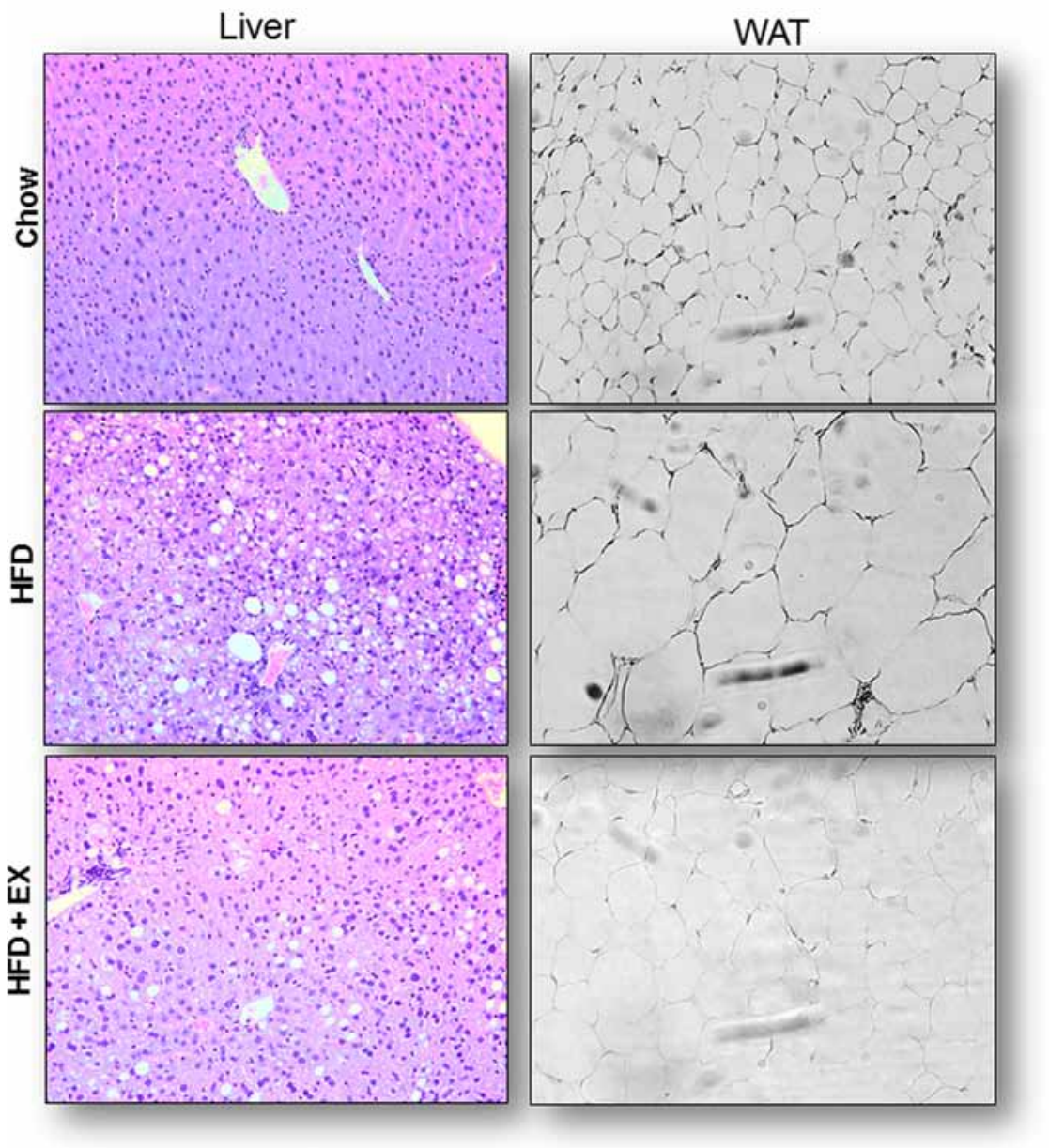

Figure 4

Liver and white adipose tissue morphology in control, HFD, and HFD + EX groups. Liver sample (left) and white adipose sample (right) $(5 \mu \mathrm{M}$ thickness) were accessed by hematoxylin and eosin staining by the end of the study (mice aged 20 weeks) in the control, HFD, and HFD + EX groups $(n=3)$. A full colour version of this figure is available at http://dx.doi.org/10.1530/ JOE-15-0510. increased compared with the control group; however, voluntary exercise training reduced the adipocytes size in the HFD+EX group (Fig. 4, right).

\section{Effect of long-term voluntary exercise training on HFD-impaired central leptin signaling}

To determine whether the long-term voluntary running wheel exercise training can improve the hypothalamic function that controls energy metabolism, we measured leptin-induced phosphorylation of STAT3 in the hypothalamus. Leptin-induced phosphorylation of STAT3 in the ARC and VMH was almost completely blunted in the HFD group compared with the control group ( $54 \pm 3$ vs $5 \pm 1$ counts per slice). Voluntary exercise training partially restored leptin-induced STAT3 phosphorylation in the HFD-treated mice $(19 \pm 2$ vs $5 \pm 1$ counts per slice), suggesting that voluntary exercise training improves central leptin signaling (Fig. 5). Printed in Great Britain

\section{Effect of long-term HFD and voluntary exercise training on POMC-expressing neurons}

To determine the effect of HFD and exercise training on POMC-expressing neurons, immunolabeling with an anti-POMC antibody was assessed. It was found that 12 weeks of HFD significantly reduced the number of POMC neurons in the hypothalamus $(26 \pm 3$ counts per slice in the control group vs $16 \pm 2$ counts per slice in the HFD group); however, long-term voluntary exercise training remarkably restored the number of POMC neurons in the HFD + EX group $(23 \pm 2$ counts per slice in the HFD+EX group vs $16 \pm 2$ counts per slice in the HFD group; Fig. 6).

\section{Long-term voluntary exercise training restores HFD-damaged neuronal proliferation in the hypothalamus}

To elucidate the potential mechanism of HFD- and exercise-induced POMC-expressing neuron alteration, an endogenous proliferative marker Ki67 was used to determine

Published by Bioscientifica Ltd. 
A
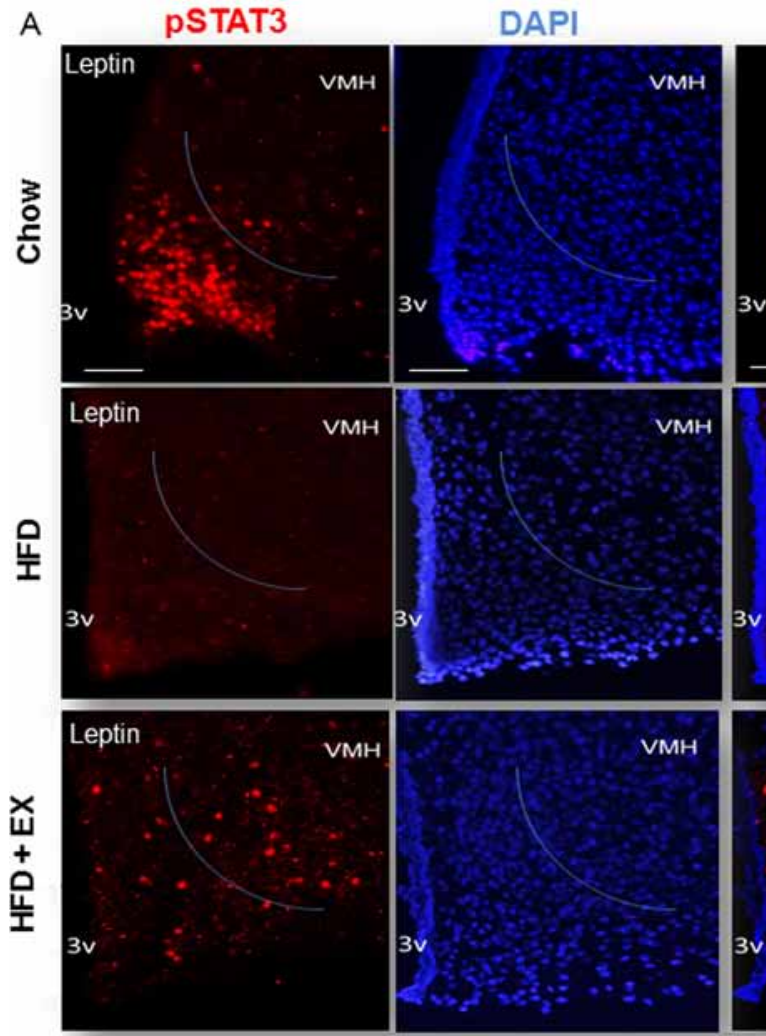

Merged
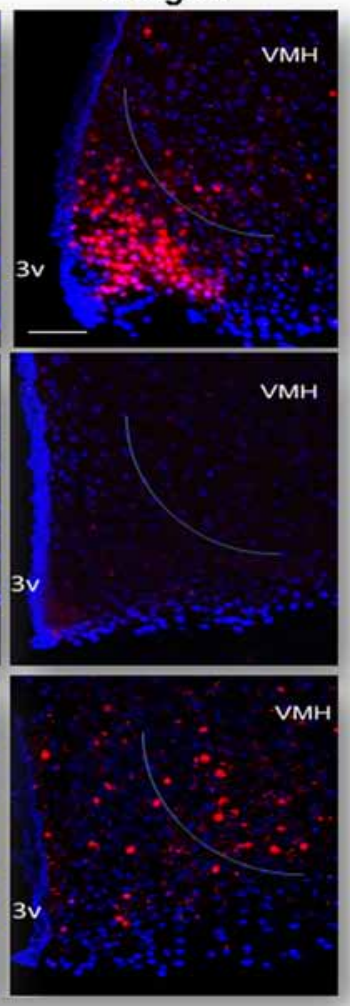

B Leptin inducedphosphorylation of STAT3

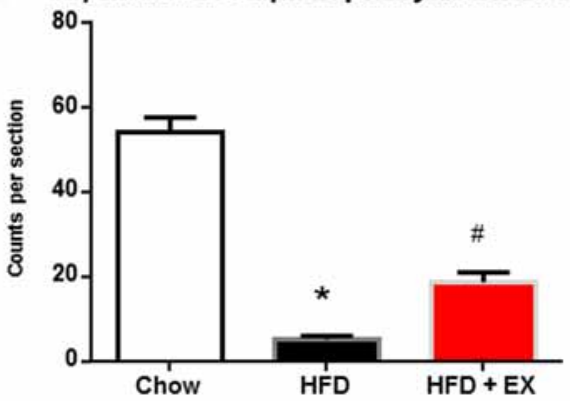

\section{Figure 5}

Long-term voluntary exercise training improves leptin signaling in arcuate of hypothalamus of HFD group. (A) Phosphorylation of STAT3 of hypothalamic sections from the control, HFD, and HFD + EX groups at 20 weeks of age $(n=3)$.

(B) Quantification of leptin-induced pSTAT3 in mediobasal hypothalamus among three groups, $* P<0.05$ vs control group, ${ }^{*} P<0.05$ vs HFD group $3 \mathrm{~V}$, third ventricle; $\mathrm{VMH}$, ventromedial hypothalamus; scale bars represent $50 \mu \mathrm{M}$. neuronal proliferation. Under high-fat conditions, the Ki67positive cells showed significantly decreased proliferation compared with the control group ( $8 \pm 1$ counts per slice in the control group vs $2 \pm 2$ counts per slice in the HFD group). It was found that 12 weeks of voluntary exercise training significantly restored the loss of cell proliferation in the hypothalamus ( $4 \pm 1$ counts per slice in the HFD+EX group vs $2 \pm 2$ counts per slice in the HFD group) (Fig. 7). Long-term voluntary exercise training reduces HFD-induced apoptosis in POMC-expressing neurons in the hypothalamus. To further investigate the potential mechanism of HFD- and exerciseinduced POMC-expressing neuron alteration, TUNEL assay was performed to determine the neuronal apoptosis among the three groups (Fig. 8). Although there was no apparent cell apoptosis occurring in the ARC of the control group, 12-week HFD significantly increased cell apoptosis, especially in the ARC, and voluntary exercise training strongly protected the HFD-induced apoptosis in this area. Furthermore, the apoptosis that specifically occurred in the POMC neurons was reduced by more than half in the exercise training group with HFD (10 \pm 3 counts per slice in the HFD group vs $4 \pm 2$ counts per slice in the HFD+EX group).

\section{Discussion}

Although over the past decade we have gained a better understanding of CNS function in regulating food

Published by Bioscientifica Ltd. 
A
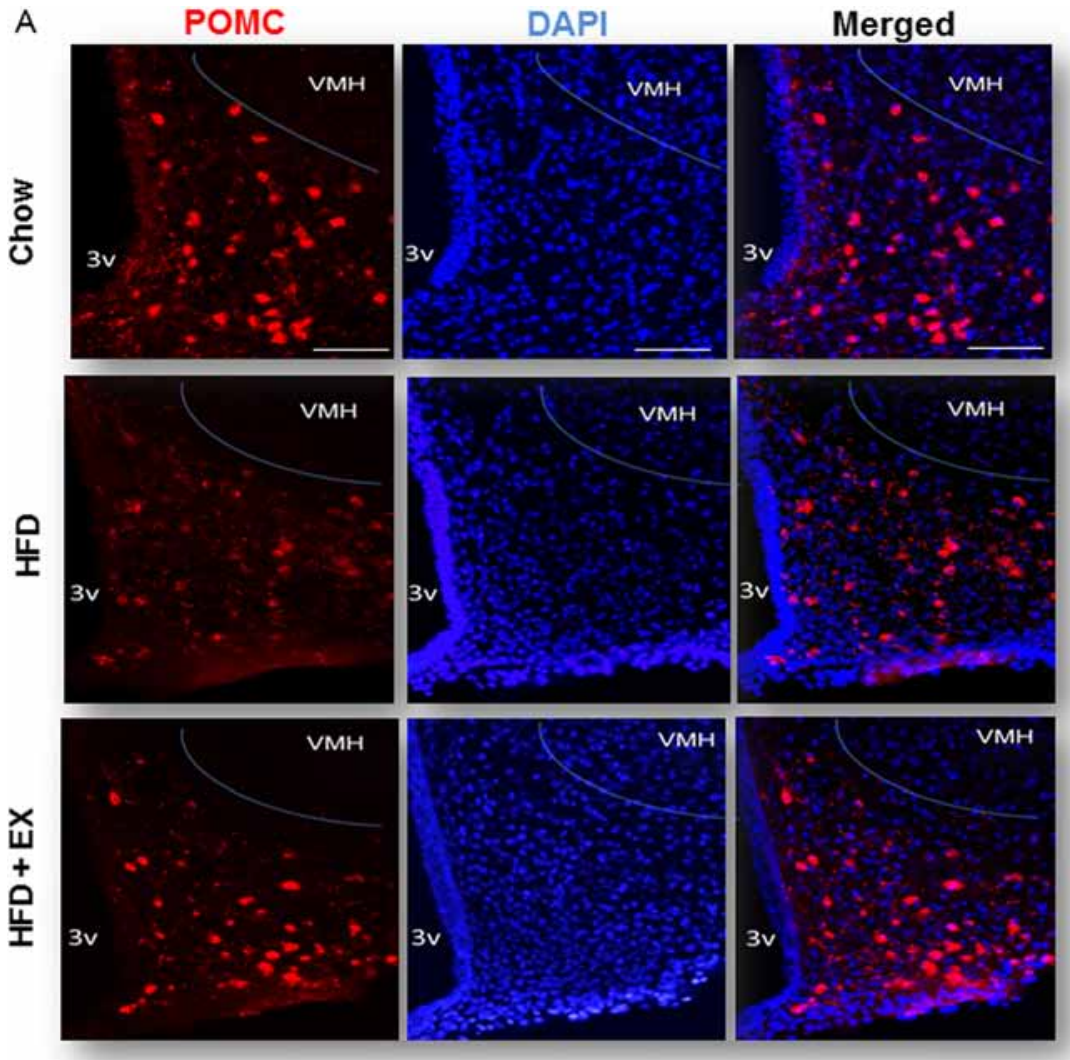

B

POMC expressing neurons

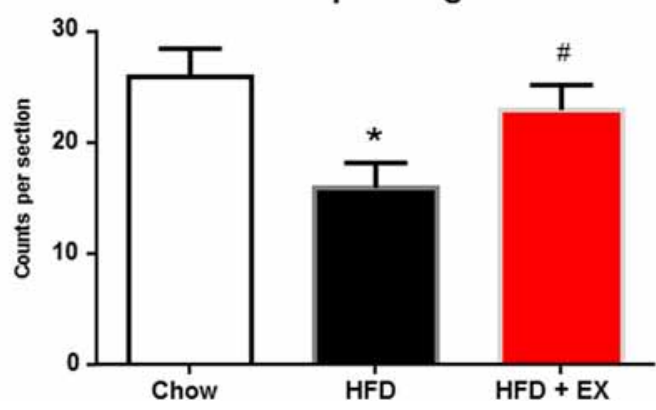

intake and body weight homeostasis (Morton et al. 2006, Mayers \& Olson 2012), a gap of knowledge exists detailing how exercise training mechanistically induces weight loss via neurological control of energy balance and body weight in obese subjects. Given the facts, certain areas within the hypothalamus, such as ARC, VMH, DMH, and PVH, play important roles in regulating systemic metabolic homeostasis. However, to date, emerging evidence has shown that exercise training-induced improvements are associated with molecular changes that improve metabolic functions in most peripheral tissues, such as increased glucose uptake in skeletal muscle and adipose tissue as well as decreased lipids accumulation in adipose tissue and the liver, all of which contribute to enhanced insulin

\begin{abstract}
Figure 6
Long-term voluntary exercise training increases POMC-expressing neurons in the ARC of the hypothalamus of HFD group.

(A) Immunofluorescence of POMC-expressing neurons of hypothalamic sections from the control, HFD, and HFD+EX groups at 20 weeks of age $(n=3)$. (B) Quantification of POMC-expressing neurons in the mediobasal hypothalamus among three groups, ${ }^{*} P<0.05$ vs control group, $\# P<0.05$ vs HFD group. $3 \mathrm{~V}$, third ventricle; $\mathrm{VMH}$, ventromedial hypothalamus; scale bars represent $50 \mu \mathrm{M}$.
\end{abstract}

sensitivity. Although there is an increasing amount of studies demonstrating that exercise training enhances the brain function, including the effects of exercise on learning and memory in hippocampal neurons, the role of exercise training in improving metabolic function via CNS-mediated pathways has not yet been fully understood. Thus, it is worthwhile to investigate the CNS-associated mechanism(s) of exercise training to improve metabolic function, particularly under diet-induced obesity conditions. In this study, we demonstrated that, first, HFD-induced body weight gain and adiposity are reversed by voluntary exercise training mainly through increased energy expenditure despite normal energy intake, and secondly, these effects may be associated with protection of POMC neurons and

Published by Bioscientifica Ltd. 
A
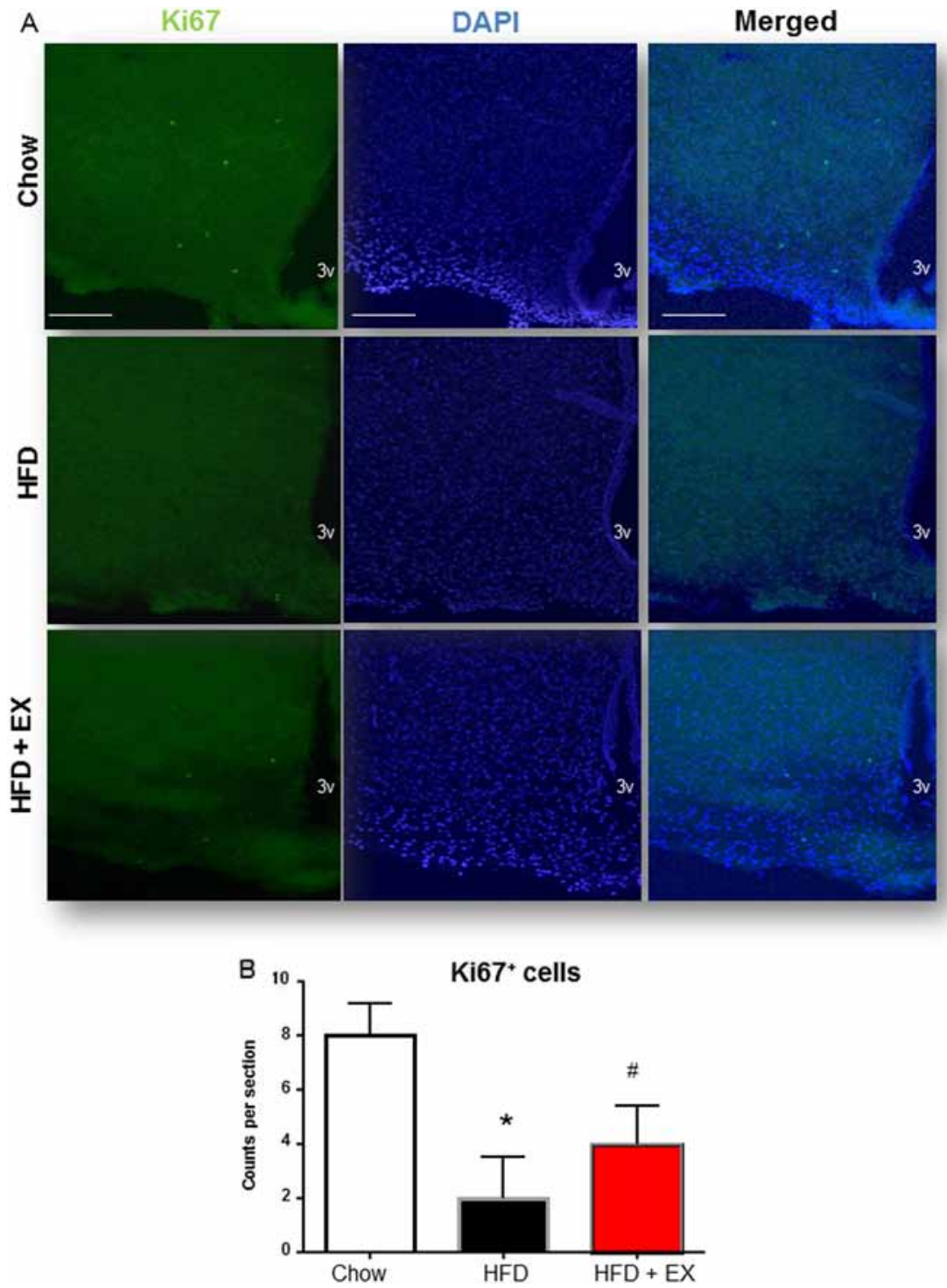

enhanced hypothalamic function response to leptin by voluntary exercise training under HFD conditions.

In the brain, POMC-expressing neurons are mainly located in the ARC of the hypothalamus and in the nucleus of solitary tract (NTS) in the brain stem. Genetically, when a null mutation of Pomc gene is generated by targeting a gene in embryonic stem cell, hyperphagic and obesity phenotypes are displayed (Yaswen et al. 1999). Human patients lacking POMC also confirm this obesity phenotype (Kruse et al. 1998). Furthermore, a recent study has been published by Zhan and coworkers using the designer receptor exclusively activated by designer drugs system to selectively remove POMC-expressing neurons in these two areas. These researchers found that postnatal ablation of POMC neurons in the ARC nucleus

\section{Figure 7}

Long-term voluntary exercise training restores HFD-damaged neuronal proliferation in hypothalamus. (A) Immunofluorescence of Ki67-positive cells of hypothalamic sections from the control, HFD, and HFD + EX groups at 20 weeks of age $(n=3)$. (B) Quantification of Ki67-positive cells in the mediobasal hypothalamus among three groups, $* P<0.05$ vs control group, ${ }^{\# P}<0.05$ vs HFD group. $3 \mathrm{~V}$, third ventricle; scale bars represent $50 \mu \mathrm{M}$. (but not in the NTS) increased food intake, reduced energy expenditure, and ultimately resulted in obesity and metabolic and endocrine disorders (Zhan et al. 2013). Taken together, these findings indicate the importance and necessity of ARC POMC-expressing neurons in controlling whole-body homeostasis. An HFD rapidly induces neuron injury and eventually causes chronic inflammation in the hypothalamus, as confirmed by obese human subjects' MRI data (Thaler et al. 2012). In the brain, POMC-expressing neurons are specifically and preferentially affected by an HFD in the ARC (Li et al. 2012). We hypothesize, thus, that damage to a critical neuronal type (POMC) for body weight control might play a role in obesity, and exercise training may play a role to prevent the damage induced by a HFD. 

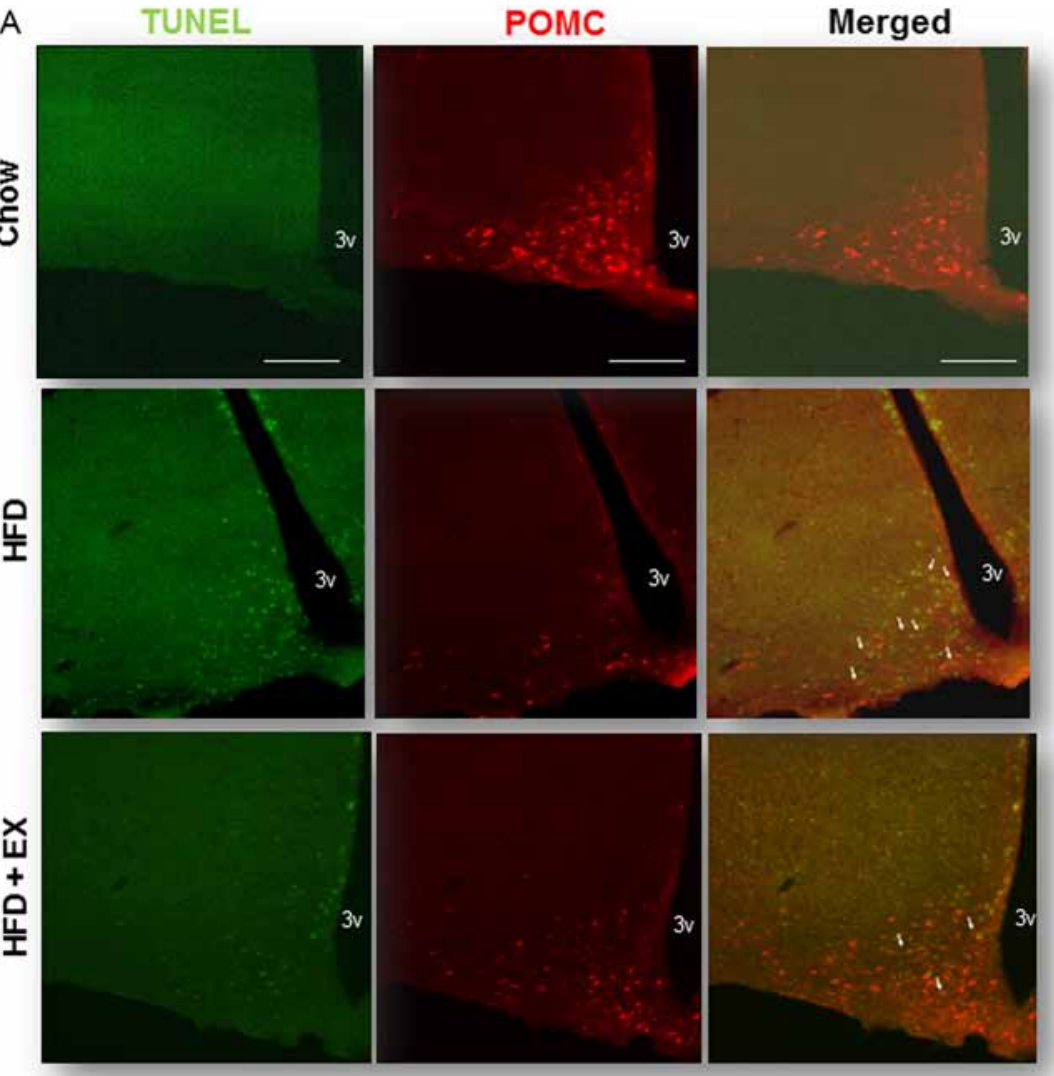

B Apoptosis in POMC expressing neuron

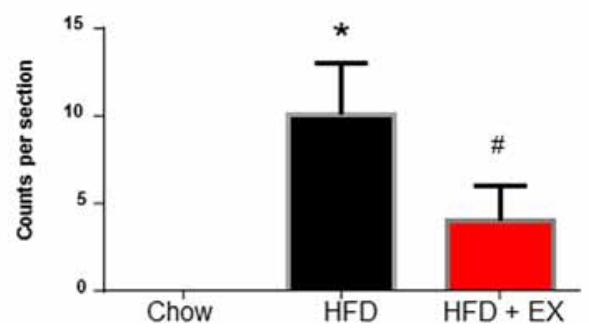

Figure 8

Long-term voluntary exercise training reduces HFD-induced apoptosis in POMC-expressing neurons in hypothalamus. (A) Immunofluorescence of apoptotic positive cells and POMC-expressing neurons of hypothalamic sections from the control, HFD, and HFD + EX groups at 20 weeks of age $(n=3)$.

(B) Quantification of apoptotic positive cells in POMC-expressing neurons in the mediobasal hypothalamus among three groups. White arrows indicate apoptotic positive cell in POMC expressing neurons. ${ }^{*} P<0.05$ vs control group, ${ } P<0.05$ vs HFD group. $3 \mathrm{~V}$, third ventricle; scale bars represent $50 \mu \mathrm{M}$.
POMC-expressing neurons control both energy intake and energy expenditure. One interesting finding of this study is that there is no food intake difference between the HFD and HFD+EX groups observed, despite the fact that exercise training restored POMC-expressing neurons significantly. This might be due to counterpart effects, because POMC neurons are not the only neurons affected by an HFD. In fact, the orexigenic agouti-related peptide (AgRP)-expressing neuron also resides in the ARC that controls food intake, and ablation of AgRP neuron in adult mice has been shown to result in significantly reduced food intake (Luquet et al. 2005). It has also been reported that an HFD induces apoptosis of AgRP neuron (Moraes et al. 2009). These results suggest that long-term HFD and exercise training may have broad effects on both orexigenic and anorexigenic neurons in the ARC. Consistent with our findings, it has been reported that 6-week voluntary exercise training promotes leanness and prevents diet-induced obesity by increasing energy expenditure but not energy intake. These effects are associated with changes in the CNS centers that control energy homeostasis, particularly in the subset of neurons in the $\mathrm{VMH}$, which is another primary satiety center in the hypothalamus, further proved the notion that exercise training may have broader effects than just particular neurons in the hypothalamus. In the same study, HFD-induced central leptin resistance, revealed by measuring food intake after central administration of leptin, was also significantly improved when followed by voluntary exercise training (Krawczewski et al. 2011). This suggests a potential mechanism of CNS-associated effects of

Published by Bioscientifica Ltd. 
exercise training on metabolic function. Our study further explored this notion by demonstrating central leptin signaling by immunolabeling phosphorylation of STAT3, a classic downstream pathway marker of leptin signaling transduction in the hypothalamus. We found that 12-week HFD treatment dramatically reduced pSTAT3 signals in the ARC and VMH nuclei, and that this impairment was significantly improved by voluntary exercise training. This was also true with even shorter periods of exercise training in diet-induced obesity rats. Patterson and coworkers showed that 3 weeks of post-weaning exercise training reduced body weight gain and adiposity in selectively bred diet-induced obese rats, and that these effects are associated with increased leptin-induced pSTAT3 expression in the ARC area (Patterson et al. 2009). Leptin directly activates hypothalamic POMC-expressing neurons (Cowley et al. 2001), and deficiency of leptin signaling pathway activation in POMC-expressing neurons results in increased body weight (Balthasar et al. 2004).

We investigated the effects of exercise training in POMCexpressing neurons directly. A 12-week HFD significantly decreased the number of POMC-expressing neurons, but this decrease was not observed in the HFD+EX group. To the best of our knowledge, this is the first study to show that voluntary exercise training has a beneficial role on POMC-expressing neuron turnover. Notably, turnover is the balance between neurogenesis and neuronal death. Most recently, neurogenesis has been described in the hypothalamus and has been shown to participate in the response of hypothalamic neuronal circuits to metabolic status (Kokoeva etal. 2005). Emerging evidence suggests that, in addition to the hippocampal area, active neurogenesis takes place in other regions of the adult rodent brain, including the hypothalamus, where a potential neurogenic niche has been identified. In adults, neurogenesis occurs at low rates in different areas of the brain. Moreover, the new neurons produced through adult life seem to contribute to physiological function of the entire body (Lee et al. 2012). Neurogenesis in the ARC has shown to be essential for reducing and sustaining reduced body weight, and an HFD was shown to disrupt this neuronal proliferation process in mice with diet-induced obesity (Li et al. 2012, McNay et al. 2012). To investigate the potential role of exercise in enhancing neuronal proliferation in the ARC that possibly promotes POMC-expressing neurons, we measured the endogenous proliferative marker Ki67's expression in the ARC area among the three groups. Consistent with previous findings, we found that neurogenesis occurs in adults at very low rates in different areas of the brain. We could detect very few Ki67-positive cells in the ARC area of mice in the control group; interestingly, there was a significant reduction of Ki67-positive cells in the same area of the HFD group. Voluntary exercise training significantly restored the Ki67-positive cells in the hypothalamus. However, one limitation of this study is that Ki67 can only be detected in premature cells, thus making it impossible to colabel along with mature cell markers to determine their final destination. Although we observed that there is a significant increase of Ki67-positive cells in the ARC of the HFD+EX group compared with the HFD group, the total net contribution to the increase of POMC-expressing neurons associated with reduction of body weight and adiposity remains mostly unclear. Future studies should address the specificity of exercise training-induced neuronal proliferation and weigh the contribution of these proliferative cells that regulate whole-body metabolism.

Similar to our findings, Borg and coworkers have recently reported that 7 days of exercise training increased hypothalamic cell proliferation 3.5-fold above the sedentary mice. However, blocking cell proliferation via administration of the mitotic blocker cytosine-1- $\beta$-D-arabinofuranoside (AraC) did not affect food intake or body mass in obese mice, indicating that the proliferation of new neurons is not required for maintaining whole-body homeostasis by exercise training (Borg et al. 2014). Therefore, to elucidate the potential mechanism of nutrition and exercise training in altering POMC-expressing neurons, we next investigated neuronal death by using a TUNEL assay. It has been reported that overnutrition, such as a long-term HFD, could induce hypothalamic cell inflammation via endoplasmic reticulum (ER) stress, and inflammatory signal transduction can lead to the activation of apoptotic signaling pathways (Zhang et al. 2008). In contrast to the neuronal proliferative study, the TUNEL assay revealed that although there is no obvious apoptosis occurring in the control group, in the HFD group we found that more cell apoptosis accumulated in the ARC area of the hypothalamus, and most strikingly, we also observed that voluntary exercise remarkably reduced neuronal apoptosis compared with the HFD group, leading to a potential protective mechanism in which exercise training rescues HFD-induced neuronal loss. Along with our findings, Yi and coworkers have reported that 26 weeks of moderate treadmill exercise training prevented Western-style dietinduced hypothalamic inflammation by decreasing microglia activation in the ARC, supporting the idea of exercise training in repairing neuronal damage in the hypothalamus (Yi et al. 2012). The possible molecular mechanism of HFD-induced ER stress might be associated

Published by Bioscientifica Ltd. 
with IKK- $\beta / \mathrm{NF}-\mathrm{kB}$ pathway in the hypothalamus, which an HFD could activate leading to a progression of ER stress in the hypothalamus and therefore impairing insulin and leptin signaling, thus resulting in energy imbalance (Zhang et al. 2008). Thus, IKK- $\beta / \mathrm{NF}-\mathrm{\kappa B}$ in the hypothalamus is a potential target pathway for exercise training-associated benefits in the hypothalamus. Interestingly, interleukin 6 (IL6) is a cytokine that has both proinflammatory and anti-inflammatory functions along with its metabolic effects on food intake suppression, energy expenditure induction, and body weight and adiposity reduction. The actions of IL6 might mediate to suppression of IKK- $\beta / \mathrm{NF}-\mathrm{\kappa B}$ activation in the hypothalamus and thus help to maintain normal function (Ropelle et al. 2010). Notably, the IL6 is a highly exercise inducible cytokine in skeletal muscle (during contraction) as well as in neurons located in the hypothalamus. Indeed, the increased hypothalamic IL6 expression was observed in exercisetrained rats (Ropelle et al. 2010), suggesting a possible molecular mechanism that exercise improves metabolic function at least partially via the IL6-IKK- $\beta / \mathrm{NF}-\mathrm{kB} / \mathrm{ER}$ stress-mediated pathway, thus preventing HFD-induced neuronal inflammation/apoptosis and eventual neuron loss. BDNF is another element that influences neuronal survival and differentiation (Binder \& Scharfman 2004) and has a strong metabolic function in regulating body weight (Xu et al. 2003). It has been reported that HFD reduces hippocampal levels of BDNF (Molteni et al. 2002). Interestingly, BDNF can be induced in the CNS by exercise and exercise training (Molteni et al. 2004, Huang et al. 2006), leading us to suspect that BDNF also plays an important role in protecting neurons from HFD-induced damages in the hypothalamus, which might be further enhanced by exercise training. Taking these facts together, it would be intriguing to investigate the relationship between exercise-induced hypothalamic IL6 and BDNF signaling in conjunction with hypothalamic function in the context of energy homeostasis.

Overall, this study has demonstrated the effects of voluntary exercise training on metabolic function that may be associated with CNS-mediated pathways by protecting POMC-expressing neurons and enhancing leptin signaling in the ARC nucleus of the hypothalamus. Although the cellular and molecular mechanisms behind this phenomenon need to be explored further, our findings regarding CNS-mediated pathways that potentially mimic the effect of exercise training to prevent hypothalamic neuron loss would make a highly logical and desirable strategy for the prevention and treatment of obesity in humans.
Declaration of interest

The authors declare that there is no duality of interest associated with this manuscript.

\section{Funding}

This work was supported by start-up funds from East Carolina University (Greenville, NC, USA) to H Huang.

\section{Author contributions}

$B \mathrm{~L}, \mathrm{~K} D, T \mathrm{M}, \mathrm{W} \mathrm{D}, \mathrm{M} \mathrm{A}, \mathrm{E} \mathrm{L}$, and $\mathrm{H} \mathrm{H}$ performed all the experiments and analyzed data; $\mathrm{D} Z \mathrm{Z}$ helped to perform the exercise training experiment. $\mathrm{H} \mathrm{H}$ designed and wrote the manuscript. All the coauthors reviewed and approved the submission of the manuscript.

\section{Acknowledgments}

The authors thank Wendy Beachum and Ashley Busuda for their excellent administrative help.

\section{References}

Bagnol D, Lu X, Kaelin CB, Day HEW, Ollmann M, Gantz I, Akil H, Barsh GS \& Watson SJ 1999 Anatomy of an endogenous antagonist: relationship between agouti-related protein and proopiomelanocortin in the brain. Journal of Neuroscience 26 1-7.

Balthasar N, Coppari R, McMinn J, Liu SM, Lee CE, Tang V, Kenny CD, McGovern RA, Chua SC Jr, Elmquist JK, et al. 2004 Leptin receptor signaling in POMC neurons is required for normal body weight homeostasis. Neuron 24 983-991. (doi:10.1016/j.neuron.2004.06.004)

Binder DK \& Scharfman HE 2004 Brain-derived neurotrophic factor. Growth Factors 22 123-131. (doi:10.1080/08977190410001723308)

Borg ML, Lemus M, Reichenbach A, Selathurai A, Oldfield BJ, Andrews ZB \& Watt MJ 2014 Hypothalamic neurogenesis is not required for the improved insulin sensitivity following exercise training. Diabetes 63 3647-3658. (doi:10.2337/db13-1762)

Cowley MA, Smart JL, Rubinstein M, Cerdán MG, Diano S, Horvath TL, Cone RD \& Low MJ 2001 Leptin activates anorexigenic POMC neurons through a neural network in the arcuate nucleus. Nature $\mathbf{2 4}$ 480-484. (doi:10.1038/35078085)

Dishman RK 1997 Brain monoamines, exercise, and behavioral stress: animal models. Medicine and Science in Sports and Exercise 29 63-74.

Erickson KI, Voss MW, Prakash RS, Basak C, Szabo A, Chaddock L, Kim JS, Heo S, Alves H, White SM, et al. 2011 Exercise training increases size of hippocampus and improves memory. PNAS 108 3017-3022. (doi:10.1073/pnas.1015950108)

Fuss J, Ben Abdallah NM, Vogt MA, Touma C, Pacifici PG, Palme R, Witzemann V, Hellweg R \& Gass P 2010 Voluntary exercise induces anxiety-like behavior in adult C57BL/6J mice correlating with hippocampal neurogenesis. Hippocampus 20 364-376. (doi:10.1002/ hipo.20634)

Goldstein MS, Mullick V, Huddlestun B \& Levine R 1953 Action of muscular work on transfer of sugars across cell barriers: comparison with action of insulin. American Journal of Physiology 173 212-216.

Gollisch KS, Brandauer J, Jessen N, Toyoda T, Nayer A, Hirshman MF \& Goodyear LJ 2009 Effects of exercise training on subcutaneous and visceral adipose tissue in normal- and high-fat diet-fed rats. American Journal of Physiology: Endocrinology and Metabolism 297 E495-E504. (doi:10.1152/ajpendo.90424.2008)

Published by Bioscientifica Ltd. 
Greenman Y, Kuperman Y, Drori Y, Asa SL, Navon I, Forkosh O, Gil S, Stern N \& Chen A 2013 Postnatal ablation of POMC neurons induces an obese phenotype characterized by decreased food intake and enhanced anxiety-like behavior. Molecular Endocrinology 27 1091-1102. (doi:10.1210/me.2012-1344)

Huang AM, Jen CJ, Chen HF, Yu L, Kuo YM \& Chen HI 2006 Compulsive exercise acutely upregulates rat hippocampal brain-derived neurotrophic factor. Journal of Neural Transmission 113 803-811. (doi:10.1007/s00702-005-0359-4)

Huang H, Kong D, Byun KH, Ye C, Koda S, Lee DH, Oh BC, Lee SW, Lee B, Zabolotny JM, et al. 2012 Rho-kinase regulates energy balance by targeting leptin receptor signaling. Nature Neuroscience 15 1391-1398. (doi:10.1038/nn.3207)

Huang H, Lee SH, Ye C, Lima IS, Oh BC, Lowell BB, Zabolotny JM \& Kim YB 2013 ROCK1 in AgRP neurons regulates energy expenditure and locomotor activity in male mice. Endocrinology 154 3660-3670. (doi:10.1210/en.2013-1343)

Jackson KC, Wohlers LM, Valencia AP, Cilenti M, Borengasser SJ, Thyfault JP \& Spangenburg EE 2011 Wheel running prevents the accumulation of monounsaturated fatty acids in the liver of ovariectomized mice by attenuating changes in SCD-1 content. Applied Physiology, Nutrition and Metabolism 36 798-810. (doi:10.1139/h11-099)

Kokoeva MV, Yin H \& Flier JS 2005 Neurogenesis in the hypothalamus of adult mice: potential role in energy balance. Science $\mathbf{3 1 0} 679-683$. (doi:10.1126/science.1115360)

Kopelman PG 2000 Obesity as a medical problem. Nature 404 635-643. (doi:10.1038/35007508)

Krawczewski Carhuatanta KA, Demuro G, Tschöp MH, Pfluger PT, Benoit SC \& Obici S 2011 Voluntary exercise improves high-fat dietinduced leptin resistance independent of adiposity. Endocrinology 152 2655-2664. (doi:10.1210/en.2010-1340)

Kruse H, Biebermann H, Luck W, Horn R, Brabant G \& Grüters A 1998 Severe early-onset obesity, adrenal insufficiency and red hair pigmentation caused by POMC mutations in humans. Nature Genetics 19 155-157. (doi:10.1038/509)

Lee DA, Bedont JL, Pak T, Wang H, Song J, Miranda-Angulo A, Takiar V, Charubhumi V, Balordi F, Takebayashi H, et al. 2012 Tanycytes of the hypothalamic median eminence form a diet-responsive neurogenic niche. Nature Neuroscience 15 700-702. (doi:10.1038/nn.3079)

Lewis DE, Shellard L, Koeslag DG, Boer DE, McCarthy HD, McKibbin PE, Russell JC \& Williams G 1993 Intense exercise and food restriction cause similar hypothalamic neuropeptide Y increases in rats. American Journal of Physiology 264 E279-E284.

Li J, Tang Y \& Cai D 2012 IKKbeta/NF-kappaB disrupts adult hypothalamic neural stem cells to mediate a neurodegenerative mechanism of dietary obesity and pre-diabetes. Nature Cell Biology 14 999-1012. (doi:10.1038/ncb2562)

Luquet S, Perez FA, Hnasko TS \& Palmiter RD 2005 NPY/AgRP neurons are essential for feeding in adult mice but can be ablated in neonates. Science 310 683-685.

Mayers Jr MG \& Olson DP 2012 Central nervous system control of metabolism. Nature 491 357-363. (doi:10.1038/nature11705)

McNay DE, Briancon N, Kokoeva MV, Maratos-Flier E \& Flier JS 2012 Remodeling of the arcuate nucleus energy-balance circuit is inhibited in obese mice. Journal of Clinical Investigation 122 142-152. (doi:10.1172/JCI43134)

Molteni R, Barnard RJ, Ying Z, Roberts CK \& Gomez-Pinilla F 2002 A high-fat, refined sugar diet reduces hippocampal brain-derived neurotrophic factor, neuronal plasticity, and learning. Neuroscience 112 803-814. (doi:10.1016/S0306-4522(02)00123-9)

Molteni R, Wu A, Vaynman S, Ying Z, Barnard RJ \& Gómez-Pinilla F 2004 Exercise reverses the harmful effects of consumption of a high-fat diet on synaptic and behavioral plasticity associated to the action of brain-derived neurotrophic factor. Neuroscience 123 429-440. (doi:10.1016/j.neuroscience.2003.09.020)

Moraes JC, Coope A, Morari J, Cintra DE, Roman EA, Pauli JR, Romanatto T, Carvalheira JB, Oliveira AL \& Saad MJ, et al. 2009 High-fat diet induces apoptosis of hypothalamic neurons. PLoS ONE 4 e5045. (doi:10.1371/journal.pone.0005045)

Morton GJ, Cummings DE, Baskin DG, Barsh GS \& Schwartz MW 2006 Central nervous system control of food intake and body weight. Nature 443 289-295. (doi:10.1038/nature05026)

Neeper SA, Gomez-Pinilla F, Choi J \& Cotman CW 1996 Physical activity increases mRNA for brain-derived neurotrophic factor and nerve growth factor in rat brain. Brain Research 726 49-56. (doi:10.1016/0006-8993(96)00273-9)

Patterson CM, Bouret SG, Dunn-Meynell AA \& Levin BE 2009 Three weeks of postweaning exercise in DIO rats produces prolonged increases in central leptin sensitivity and signaling. American Journal of Physiology: Regulatory, Integrative and Comparative Physiology 296 R537-R548. (doi:10.1152/ajpregu.90859.2008)

Ropelle ER, Flores MB, Cintra DE, Rocha GZ, Pauli JR, Morari J, de Souza CT, Moraes JC, Prada PO, Guadagnini D, et al. 2010 IL-6 and IL-10 anti-inflammatory activity links exercise to hypothalamic insulin and leptin sensitivity through IKKbeta and ER stress inhibition. PLoS Biology 24 e1000465. (doi:10.1371/journal.pbio.1000465)

Shukla C, Koch LG, Britton SL, Cai M, Hruby VJ, Bednarek M \& Novak CM 2015 Contribution of regional brain melanocortin receptor subtypes to elevated activity energy expenditure in lean, active rats. Neuroscience 310 252-267. (doi:10.1016/j. neuroscience.2015.09.035)

Thaler JP, Yi CX, Schur EA, Guyenet SJ, Hwang BH, Dietrich MO, Zhao X, Sarruf DA, Izgur V, Maravilla KR, et al. 2012 Obesity is associated with hypothalamic injury in rodents and humans. Journal of Clinical Investigation 122 153-162. (doi:10.1172/JCI59660)

Trejo JL, Llorens-Martin MV \& Torres-Aleman I 2008 The effects of exercise on spatial learning and anxiety-like behavior are mediated by an IGF-I-dependent mechanism related to hippocampal neurogenesis. Molecular and Cellular Neurosciences 37 402-411. (doi:10.1016/ j.mcn.2007.10.016)

Tremblay A, Despres JP \& Bouchard C 1985 The effects of exercisetraining on energy balance and adipose tissue morphology and metabolism. Sports Medicine 2 223-233. (doi:10.2165/00007256198502030-00005)

Xu B, Goulding EH, Zang K, Cepoi D, Cone RD, Jones KR, Tecott LH \& Reichardt LF 2003 Brain-derived neurotrophic factor regulates energy balance downstream of melanocortin-4 receptor. Nature Neuroscience 6 736-742. (doi:10.1038/nn1073)

Yaswen L, Diehl N, Brennan MB \& Hochgeschwender U 1999 Obesity in the mouse model of pro-opiomelanocortin deficiency responds to peripheral melanocortin. Nature Medicine 5 1066-1070. (doi:10.1038/12506)

Yi CX, Al-Massadi O, Donelan E, Lehti M, Weber J, Ress C, Trivedi C, Müller TD, Woods SC \& Hofmann SM 2012 Exercise protects against high-fat diet-induced hypothalamic inflammation. Physiology \& Behavior 106 485-490. (doi:10.1016/ j.physbeh.2012.03.021)

Zhan C, Zhou J, Feng Q, Zhang JE, Lin S, Bao J, Wu P \& Luo M 2013 Acute and long-term suppression of feeding behavior by POMC neurons in the brainstem and hypothalamus, respectively. Journal of Neuroscience 20 3624-3632. (doi:10.1523/jneurosci.2742-12.2013)

Zhang X, Zhang G, Zhang H, Karin M, Bai H \& Cai D 2008 Hypothalamic IKKbeta/NF-kappaB and ER stress link overnutrition to energy imbalance and obesity. Cell 135 61-73. (doi:10.1016/ j.cell.2008.07.043)

Received in final form 11 February 2016

Accepted 1 March 2016

Accepted Preprint published online 1 March 2016 http://joe.endocrinology-journals.org

DOI: $10.1530 / \mathrm{JOE}-15-0510$
(C) 2016 Society for Endocrinology Printed in Great Britain 